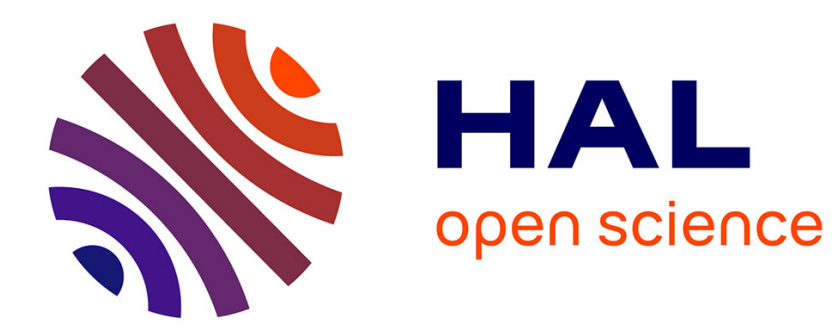

\title{
Trajectory planning for robotic maintenance of pasture based on approximation algorithms
}

\author{
C. Cariou, Zoltan Gobor
}

\section{To cite this version:}

C. Cariou, Zoltan Gobor. Trajectory planning for robotic maintenance of pasture based on approximation algorithms. Biosystems Engineering, 2018, 174, pp.219-230. hal-01914946

\author{
HAL Id: hal-01914946 \\ https://hal.science/hal-01914946
}

Submitted on 7 Nov 2018

HAL is a multi-disciplinary open access archive for the deposit and dissemination of scientific research documents, whether they are published or not. The documents may come from teaching and research institutions in France or abroad, or from public or private research centers.
L'archive ouverte pluridisciplinaire HAL, est destinée au dépôt et à la diffusion de documents scientifiques de niveau recherche, publiés ou non, émanant des établissements d'enseignement et de recherche français ou étrangers, des laboratoires publics ou privés. 


\title{
Trajectory planning for robotic maintenance of pasture based on approximation algorithms
}

\author{
Christophe Cariou $^{1 *}$ and Zoltan Gobor ${ }^{2}$ \\ 1 Irstea, UR TSCF, 9 avenue Blaise Pascal CS 20085, F-63178 Aubière, France \\ christophe.cariou@irstea.fr \\ ${ }^{2}$ LfL, Bavarian State Research Center for Agriculture, Institute for Agricultural Engineering \\ and Animal Husbandry, Vöttinger Str. 36, 85354 Freising, Germany \\ zoltan.gobor@Ifl.bayern.de \\ * Corresponding author
}

\begin{abstract}
This paper addresses the problem of trajectory planning of a mobile robot for pasture maintenance comprising mulching weeds, reseeding patches without vegetation and spreading cowpats. Based on the sensor-based acquired data (points of interest), the proposed approach is to first use an approximation algorithm for data clustering in the form of non-convex and convex hulls. These hulls are then delimited by stair-shaped limits with respect to the working width of the robot, and their centres of gravity calculated. To minimise the travelled distance between the centres of gravity of the defined areas, the Traveling Salesman Problem is addressed via an evolutionary algorithm. Finally, kinematic and dynamic properties of the robot are considered in order to generate the final trajectory. The capabilities of the proposed approaches are highlighted through the processing of several datasets.

Keywords: Mobile robot; trajectory planning; approximation algorithms; TSP
\end{abstract}

\section{Introduction}

The world population will surpass 9 billion by 2050, confronting contemporary agricultural production with new challenges (Ray, Mueller, West, \& Foley, 2013). Based on this forecasting, demand for meat and dairy products will globally increase and lead to higher retail prices. This trend is influenced by higher living standards, rising incomes and urbanisation, leading to increased consumption of higher value meat (e.g. beef) and of dairy products. Moreover, not only more quantity is demanded, but also even higher quality. By 2050, in comparison with the production levels in 2005/07, the required increase in annual meat production is estimated at $200 \mathrm{Mt}$ (OECD/FAO, 2012).

The total number of dairy farms in the EU-27 was nearly 2.5 million in 2007 with sizes varying from region to region. However, $98 \%$ of the farms owned less than 100 dairy cows, 
with an average herd size of 9.8 head per farm (Coyette \& Schenk, 2011). In such a context and in the framework of the reformed Common Agricultural Policy, EU animal products should become more competitive and ensure a fair standard of living for farmers (Coyette \& Schenk, 2011). The increased productivity will, however, remain constrained through limited resources. The productivity gains will depend on the extent to which available resources are protected, as well as research and development and on the ability of the industrial sector to adapt latest technologies such as robotics to suit farmer requirements (OECD/FAO, 2012). The introduction of robotic technology in agriculture aims to replace or support the tedious tasks carried out manually and/or to improve the quality of work and products. Field robots produced by the largest machinery manufacturers are still not commercially attractive and the great variability of situations which could be encountered under field conditions are still challenging. However, enquiries in manufacturer, farmer and public community sectors indicate that introduction of robotics in the agricultural sector can be expected in the coming years (see Böttinger, Doluschitz, Volz, Paterson, \& Jenane, 2010; Sørensen et al., 2010; Pedersen, Fountas, \& Blackmore, 2007).

Field robots able to carry out selected operations at relatively high working speeds are still rarely referenced. The required steering accuracy and reliability of the robots moving fast under off-road conditions including slopes, slippery surfaces, varying soil conditions, obstacles, and rollover-risk remain challenging, particularly under consideration of trajectory planning and control (Cariou, Gobor, Seiferth, \& Berducat, 2017; Wang \& Low, 2007). The described approaches are limited to robots moving at very low speed and based on classical control algorithms neglecting the sliding and skipping effects. Moreover, for advanced solutions, the robot must be able to detect and avoid static and dynamic obstacles during motion (e.g. in field objects such as hedges and trees, other machines, animals, humans etc.) Making mobile robots safe and reliable is an absolute prerequisite for their market introduction. Considering agricultural field robotics, the 2006/42/CE Machine Directive can be referenced. This directive demands from the manufacturer analysis of relevant and appropriate solutions and the taking of any necessary measures in order to ensure a high level of risk protection for users and other exposed persons. Furthermore, the design of robots is required to ensure protection against injury risk. Specifications for safety with agricultural machines automated to a high degree are also included within the draft standard ISO/DIS 18497.2.

In such a context, the development of modern methods is expected for pasture maintenance via field operations selectively accomplished with robots. The main problems and strategies for advanced pasture management using robotics are addressed within the ICTAGRI project i-LEED (Cariou, Gobor, Seiferth, \& Berducat, 2017; Gobor et al., 2015; Seiferth, Cariou, \& Gobor, 2016). Trajectory planning of a non-holonomic robot with kinematic and dynamic constraints is particularly challenging, and several algorithms are required to adequately process the target points in order to then generate feasible and suitable trajectories.

This paper proposes to focus more specifically on the problem of trajectory planning of 
pasture robot work covering a set of target points with weeds, cowpats and patches without vegetation. Based on these collected multi-layer data, the objectives are to: (1) define the areas of interest and assign the adequate operation to the robot by calculating the smallest area (Gobor, 2017) covering points of interest detected during the measurement; (2) find the shortest path for the robot starting from the entrance to the paddock, operating each area in the optimal order and returning to the starting point; (3) from this path, create a feasible trajectory for the pasture robot taking into account both its kinematic and dynamic constraints and its working width, in order to carry out the assigned tasks properly.

\section{Materials and Methods \\ 2.1 Datasets and pasture robot}

Considering the operative path planning issue, figure 1a presents an experimental pasture and figures $1 \mathrm{~b}$ to $1 \mathrm{e}$ the corresponding datasets based on simulation (see appendix $A$ ) for weed map, cowpats distribution and areas without vegetation (these data are supposed to come from sensor measurements).

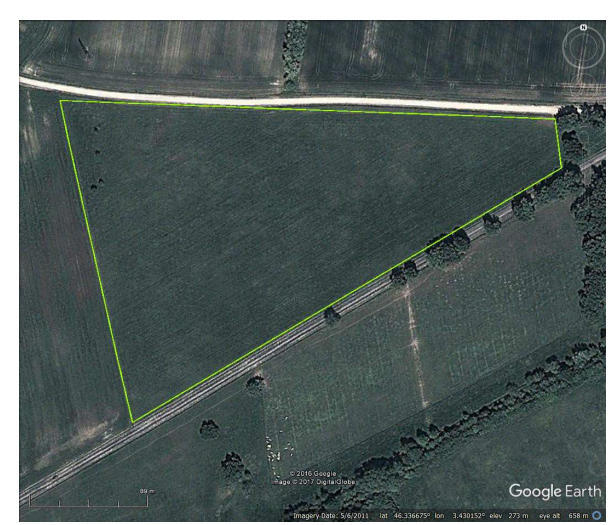

(a)



(b)

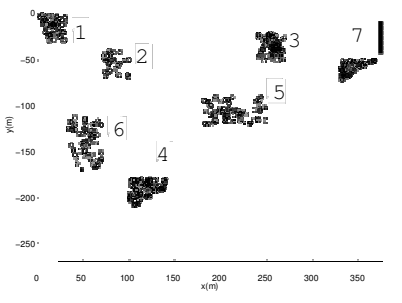

(c)

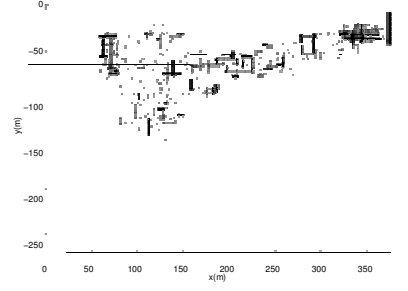

(d)

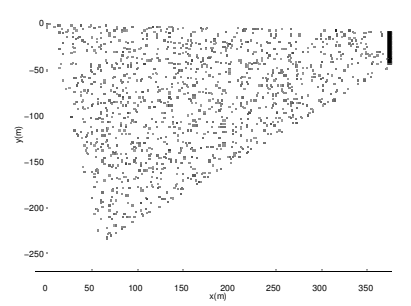

(e)

Figure 1: (a) Image of the experimental pasture - Google Earth $\mathcal{O}$ Digital Globe 2017, 46.336788 $\mathrm{N}, 3.430409^{\circ} E$, (b) Combined datasets including areas with weeds (०), without vegetation (+) and cowpats (.), (c) Detail of the areas with weeds, numbered from 1 to 7 , (d) Detail of the areas without vegetation, (e) Detail of the areas with cowpats 
The main characteristics of the pasture robot are presented in figure 2. This robot was developed within the ICT-AGRI project i-LEED (www.i-LEED.eu). It is based on a commercially available mobile platform which was originally intended for mowing public green areas using radio remote control. The front wheels are steered via linkage activated by a double acting hydraulic cylinder, and the rear wheels are driven hydraulically via a separate hydraulic circuit. The implement for mulching weeds and pasture leftovers is a flail mulcher mounted between the front and rear axles of the vehicle. A seeder was developed to spread seed mixtures on the areas without vegetation. For the project, the remote-control system was replaced by a low-level controller based on myRIO hardware (National Instruments) combined with an X-CAN adapter (Stratom) allowing the possibility of controlling all actuators of the machine directly through CANopen commands. Furthermore, a software solution developed within the i-LEED project (i-LEED GUI) in combination with the Effinav box (Effidence company) provides the possibility of carrying out autonomous navigation tasks. More details are given by Seiferth, Cariou, \& Gobor (2016).

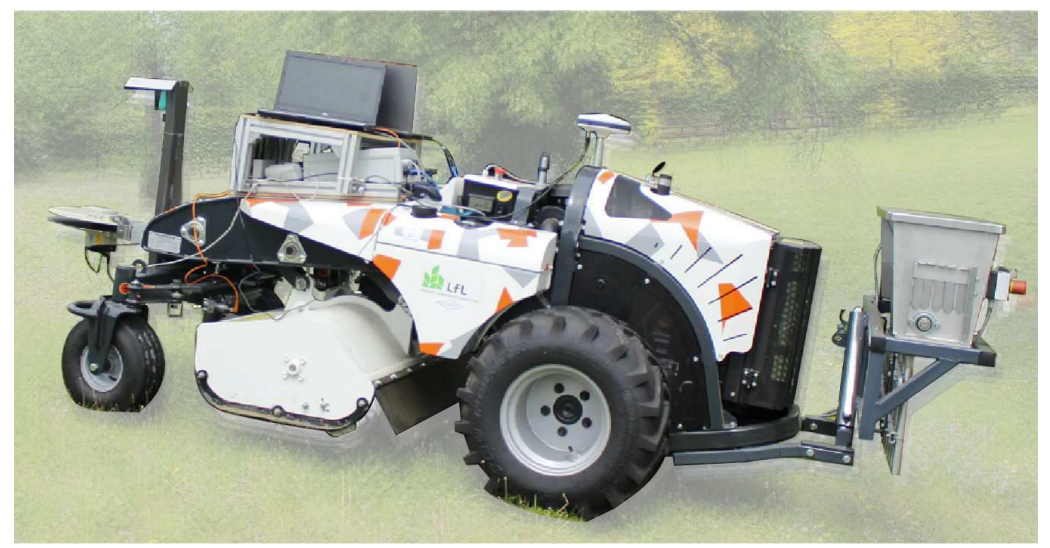

Figure 2: Pasture robot. Wheelbase: $1.56 \mathrm{~m}$, Weight: $780 \mathrm{~kg}$, Max. gradient: $30^{\circ}$, Engine: 3 cylinders diesel, Power: $24 \mathrm{kw} / 33 \mathrm{hp}$, Max. front wheels steering angle: $30^{\circ}$, Max. front wheels yaw rate: $30^{\circ} . \mathrm{s}^{-1}$, Working width: $1.2 \mathrm{~m}$

\subsection{Methods}

After calculating the non-convex and convex hulls and the centres of gravity (CoG-s) for each dataset, an evolutionary algorithm is used to define the optimal order for processing the hulls. Finally, feasible trajectories for the robot are defined to process successively the areas with weeds, cowpats and without vegetation.

\subsubsection{Prerequisite}

A prerequisite of targeted operations is an accurate and reliable identification of the areas of interest in the pasture such as areas without vegetation, areas on which fertiliser needs to be spread, leftover vegetation after grazing, or cowpats. The weed management strategies 
can be optimised through relating to the findings considering weed patches and their distribution (Krohmann, Gerhards, \& Kühbauch, 2006), and an early detection of weeds allows their selective management (Lottes, Hörferlin, Sander, \& Stachniss, 2016; Lamb \& Weedon, 1998; Christensen et al., 2009). Due to the heterogeneous distribution of weeds, maps with discrete sampling datasets can support target oriented application on the field. For example, stable spatial patterns of weed patches in location and size for all broadleaf weed species have been reported by Gerhards, Wyse-Pester, \& Mortensen (1996).

\subsubsection{Non-convex and convex hulls}

The definition of the targeted areas based on data acquired by sensors (Seiferth, Cariou, \& Gobor, 2016) can be calculated using convex hulls and non-convex hulls. The convex hull is an essential method used in mathematics and computational geometry for solving, inter alia, shape analysis problems. For certain datasets, the convex hull returns sub optimal boundaries of the set of points. This problem becomes more obvious if the area size is aimed for as the optimisation parameter during the analysis. Accordingly, the nonconvex (concave) polygon provides more accurate information. Only one convex hull can be defined on the given set of points, but many characteristic shapes can be defined by the non-convex approach. An optimal solution cannot be explicitly defined because the characteristic shape is affected by the restrictions and goals of the related problem. If the characteristic shape needs to be calculated on an unevenly distributed set of points, the problem becomes more complex considering efficiency. In this paper, an approximation algorithm is used for calculating the characteristic shape or accordingly the convex hull. Certain numbers of outliers from the dataset used for calculation will usually not imply an error in trajectory planning, especially because the final shape is usually smooth, without narrow edges on each side of the progression path. In addition, the robustness and accuracy of the data acquisition methodology also influences the dataset. Details of the methods used for finding the convex and non-convex hulls, and several examples highlighting their performance, have been presented in previous work (Gobor, 2017).

\subsubsection{Evolutionary algorithm}

Next, starting and ending at the entrance of the field, the objective is to calculate the most favorable trajectory for the robot in order to work on the areas (e.g. weed patches), identified by the CoG-s of their convex hulls and constrained with minimal traveling distance between CoG-s as optimisation parameter. The number of these points can be more or less, depending on the size of the pasture and the compromise achievable between minimal size of a patch (defined by the minimum number of detected points of interest) and the control effort for the robot to process each patch, in particular in terms of number of manoeuvres, time and energy spent. Moreover, the complexity increases rapidly with the number $n$ of points according to $(n-1) ! / 2$ (Davendra, 2010). For example, 15 points leads to 43 billion feasible paths, which means prohibitive computational time required to 
calculate each path and search for the path with the smallest distance (i.e. brute force method which consists of exhaustively calculating all possible solutions). Therefore, this issue requires solving the Traveling Salesman Problem (TSP) which features an optimisation widely addressed in the literature. Different optimisation techniques have been proposed, for instance genetic algorithms, simulated annealing, the Concorde TSP Colver, particle swarm optimisations and ant colony optimisations (see the presentation of several methods and comparative studies by Alhanjouri (2017)). Evolutionary algorithms - and particularly the genetic algorithms inspired by Darwin's theory of survival of the fittest - are powerful methods to obtain approximate solutions to the TSP (Contreras-Bolton \& Parada, 2015; Potvin, 1996). Because of this, a genetic algorithm, adapted from Kirk (2007) was used in this paper. The principle is depicted in figure 3.

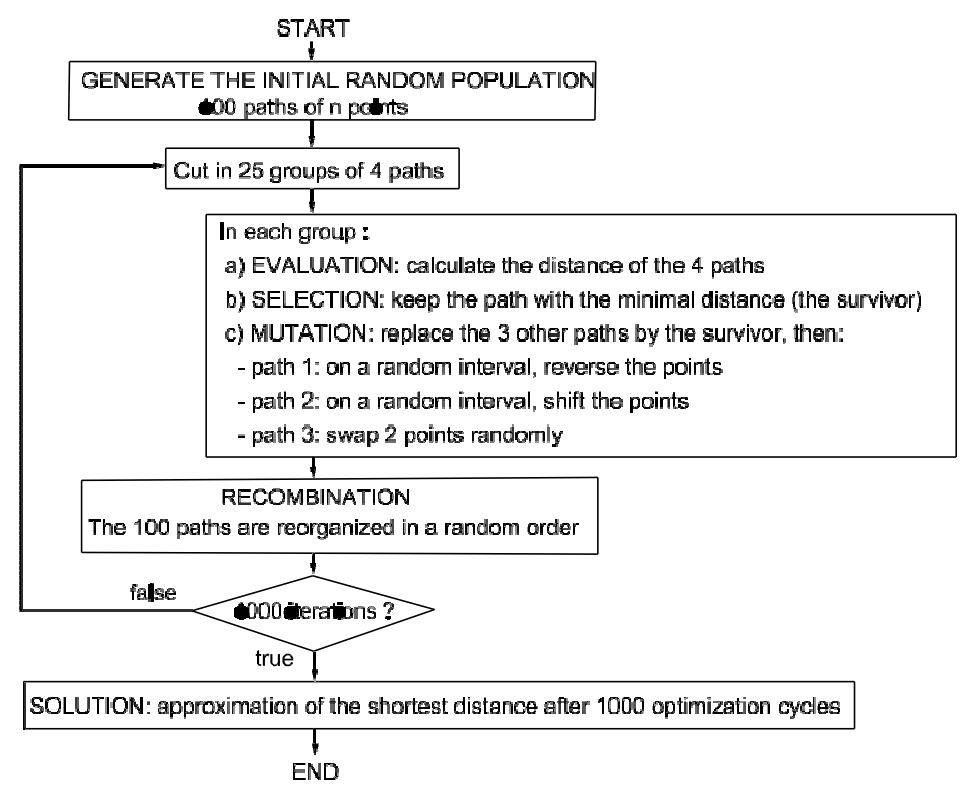

Figure 3: Genetic algorithm

Knowing the $n$ points to be reached (i.e. the starting point at the entrance of the field and $n-1$ points of interest in the pasture), it is possible to create the initial population comprising 100 paths randomly. The size of the initial population is a compromise between the calculation time and the possibility of not achieving a good approximation. The effects of the population size are addressed in Section 3. In the next step, the initial population is divided into groups of 4 paths. In each group, the optimal path called the survivor (one with the minimal Euclidean distance while assuming the lines between the points are straight) is retained, and the three others removed from the group. The removed paths are replaced by three copies of the survivor receiving the following mutations: on a random interval defined within the survivor, the points are reversed for the first mutation, shifted for the second mutation, and 2 points are swapped in the third mutation. The resulting population of 100 paths is then randomly remixed and, one again, a next iteration is operated (groups of 4 paths, selection of the 25 survivors, mutations, etc...). During the 
iterations of the algorithm (e.g. 1000 iterations), the population evolves to finally deliver an approximation of the shortest distance (optimum).

\subsubsection{Trajectory generation}

Trajectory planning for mobile robots needs to consider a number of constraints related to the motion of the robot in order to obtain a path with feasible and linear curvature variations (Munoz Ollero, 1996; Sabelhaus, Roben, Helligenaud, \& Lammers, 2013). For that, the algorithm presented in our previous work (Cariou, Gobor, Seiferth, \& Berducat, 2017 ) is used to calculate the turns and manoeuvres based on the design of segments of clothoids, and taking into account the steering capacity of the robot, its speed and the maximum defined transverse acceleration. Two cases need to be distinguished from one another: the trajectories for the complete coverage of the defined areas of interest, and the junction trajectories between these areas according to the result of the evolutionary algorithm.

- Coverage of the areas of interest. First, the driving direction for the robot to process the hull needs to be calculated. The rectangle with minimum area size containing the convex hull is examined by rotating the hull between $0^{\circ}$ and $360^{\circ}$ in $0.1^{\circ}$ steps, based on inverse calculation. At each step, the minimum and maximum coordinates in the $x$ and $y$ direction define a rectangle. At the end of the loop, the rectangle with the minimum area is retained as the solution. The longest side of the identified rectangle is finally considered as the driving direction for the robot (see figure 4). Next, following this direction, the hull is delimited by parallel stair-shaped limits while the width of the stairs corresponds to the working width of the robot. The boundaries of the stairs are called hanging points, and will correspond to the four possible entry points for the robot to process the area. After the task on one area is completed, the algorithm will look at the nearest hanging point of the next hull to be processed and will calculate the junction trajectory to reach that point.

- Junctions. To build the junction trajectories for the robot to reach the next hull to be processed, C-shaped and S-shaped trajectories are designed following the method presented in figure 5. For a C-shaped junction, $\theta_{1}$ is first calculated (angle of SE). Then, from the current position and orientation of the robot at the start point of the junction $\mathrm{S}$, the robot is first rotated in this direction. The turn is based on clothoids adapted to the robot motion constraints (Cariou, Gobor, Seiferth, \& Berducat, 2017) followed by a straight segment until the mid-distance point $M$ between points $S$ and $E$. The point $M$ can be considered as a meeting point if calculating the junction trajectory for both directions SE and ES. Finally, if at the meeting point $M$ the orientation of the two parts of trajectory are different, the turns are progressively increased until $\theta_{1}=\theta_{2}$. The same approach is applied for the S-shaped junction. 


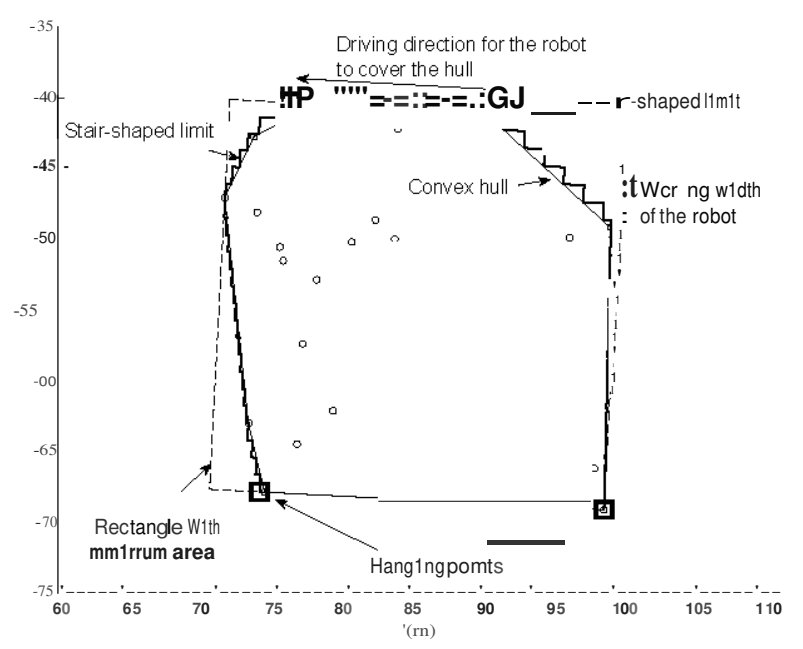

Figure 4: From the convex hull containing the points of interest (o), the driving direction, the stair-shaped limits and the hanging points can be determined.
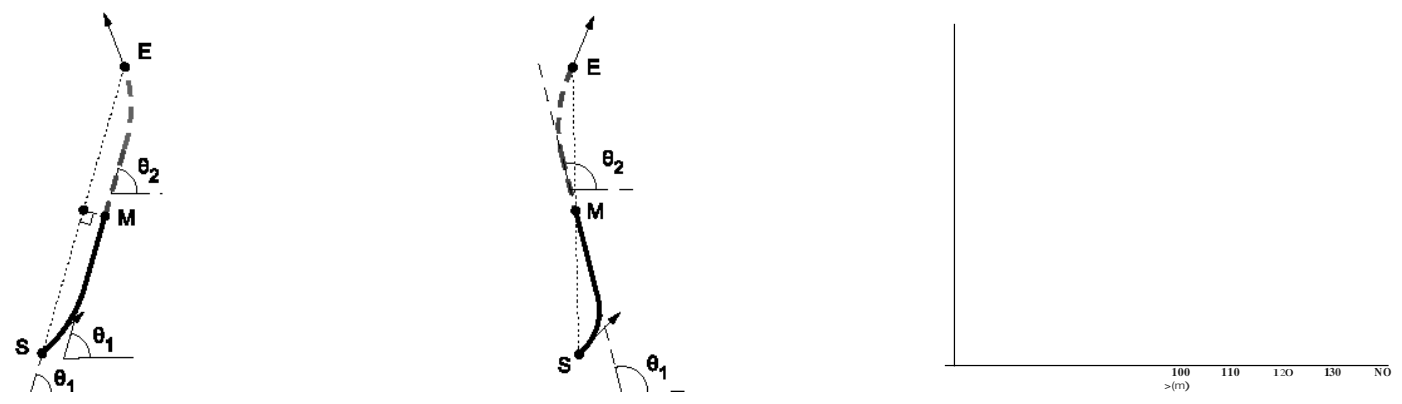

(a)

(b)

Figure 5: (a) Method to build respectively $\mathrm{C}$-shaped and $\mathrm{S}$-shaped junction trajectories. $\mathrm{S}$ is the current position of the robot, $\mathrm{E}$ is the next hanging point to reach, $\mathrm{M}$ is the meeting point at mid-distance. (b) Example of a C-shaped junction trajectory between two hanging points

\section{Results}

The different approaches presented in the previous sections (convex hulls, resolution of the TSP, trajectory generation for complete coverage of the hulls and junction trajectories) have been applied to plan the trajectories of the pasture robot depicted in figure 2 to successively carry out the assigned tasks on the target points with weeds, without vegetation and cowpats presented in figure $1 \mathrm{~b}$.

\subsection{Non-convex and convex hulls}

The non-convex and convex hulls and CoG-s were calculated for the datasets. The resulting hulls calculated, using the method described in the previous section, on the datasets containing information about detected weeds and areas without vegetation (see figures le and ld) are presented in figure 6. 


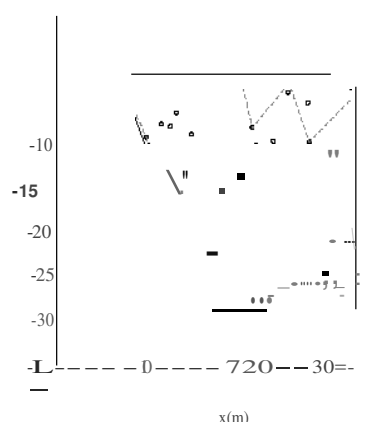

(a)

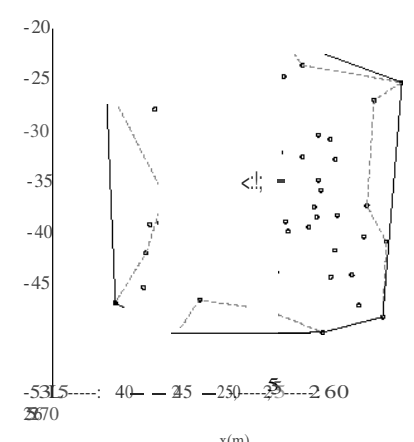

(c)

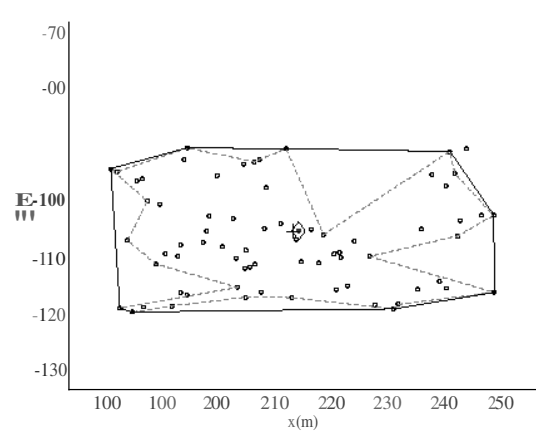

(e)

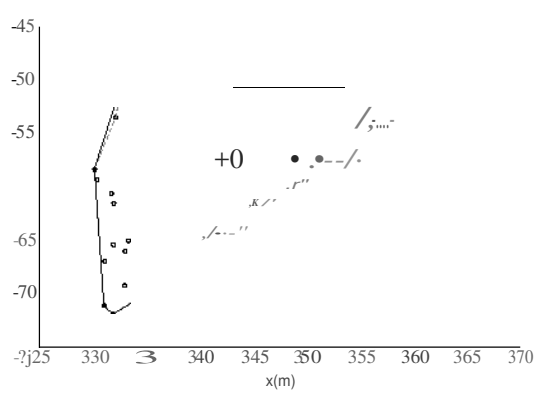

(g)

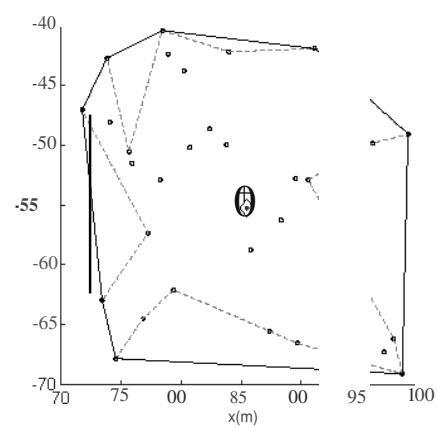

(b)

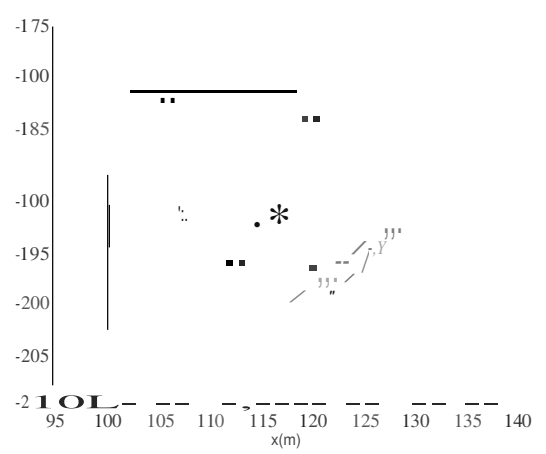

(d)

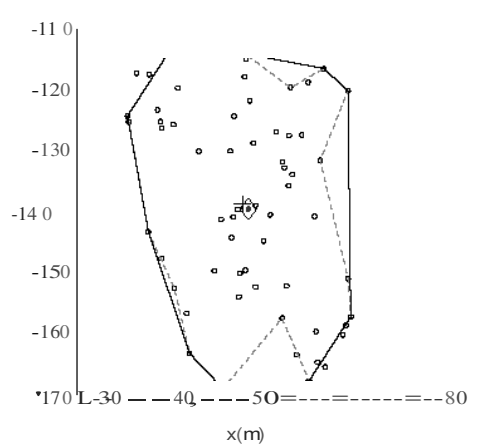

(f)

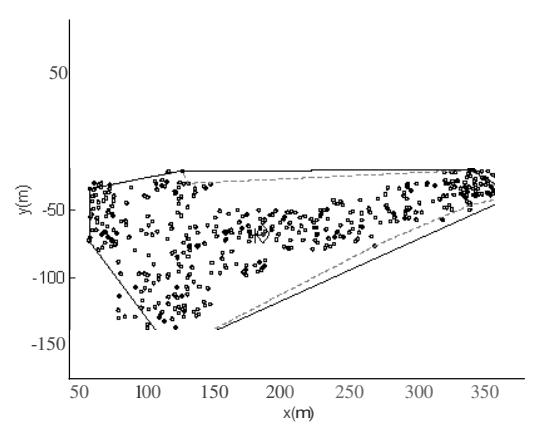

(h)

Figure 6: Determination of non-convex (--) and convex hulls $(-)$ for the areas with weeds (a to g), cor responding to the areas numbered from 1 to 7 on figure le, and for the area without vegetation (h). The CoG-s for respectively non-convex and convex hulls are noted $(+)$ and $(\diamond)$. 


\subsection{Trajectory planning}

Results of calculating driving direction and hanging points for the areas with weeds are presented in figure 7. The genetic algorithm for the TSP gives the path "3 216457 " for the weed processing. Figure 8 presents the entire path planned for the pasture robot with $1.2 \mathrm{~m}$ working width. Figure 9 presents the planned trajectories considering areas without vegetation and areas with cowpats.



Figure 7: Hanging points (D) and desired driving directions calculated for the dataset considering areas with weeds.

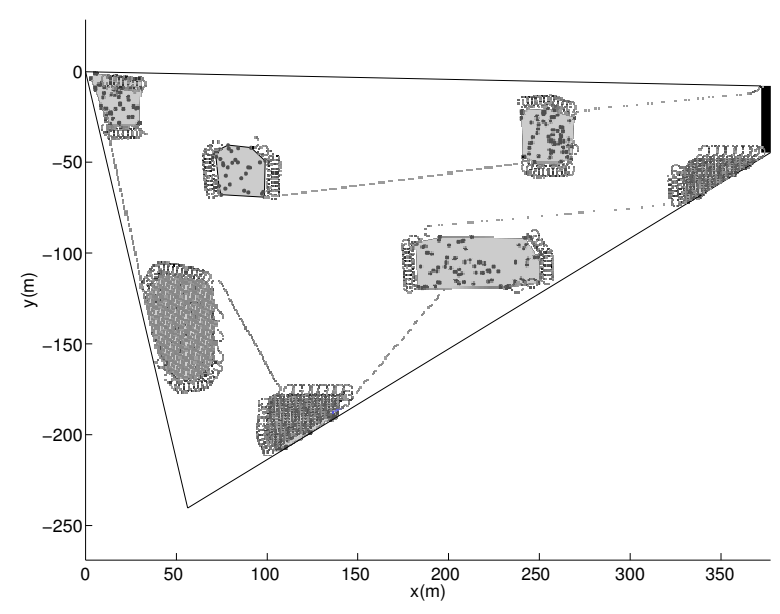

(a)

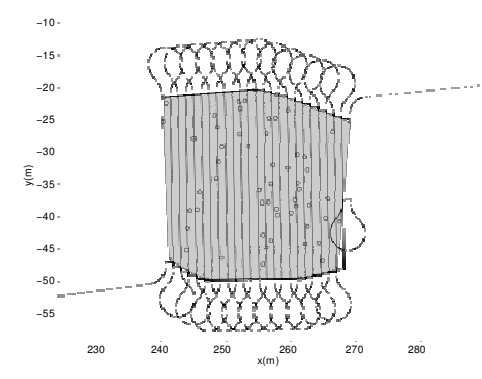

(b)

Figure 8: Planned trajectories for the pasture robot considering areas with weeds. (a) Entire path. (b) Zoom on the coverage trajectory of the first processed area. 


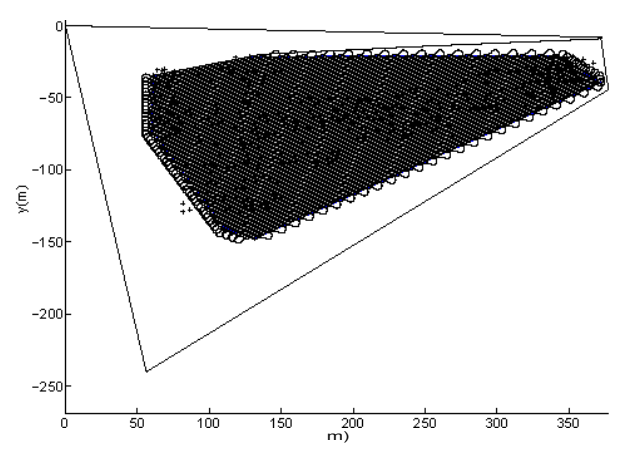

(a)

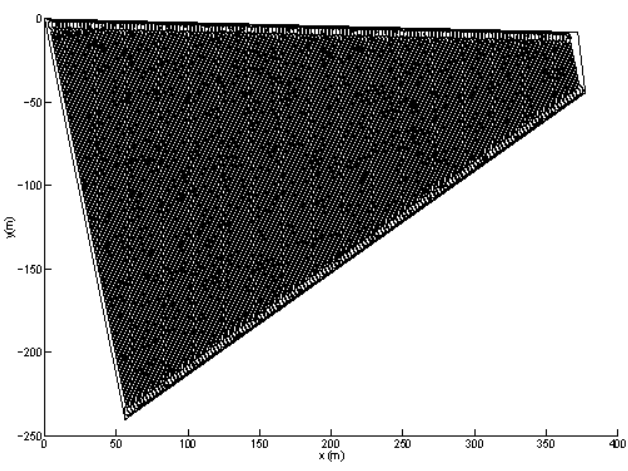

(b)

Figure 9: Planned trajectories for the pasture robot considering areas without vegetation (a) and areas with cowpats (b).

\subsection{Evolutionary algorithm}

Finally, results of the testing of the evolutionary algorithm are presented in table 1, table 2 and table 3, highlighting the necessity to increase the initial population size w.r.t. the num ber of points to be processed in order to increase the possibility of identifying a good approximation of the path with the smallest distance.

242

\begin{tabular}{|c|c|c|}
\hline \multicolumn{3}{|c|}{$\begin{array}{l}\text { No. of points to be reached: } 10 \\
\text { No. of possible paths: } 181440\end{array}$} \\
\hline \multicolumn{3}{|c|}{$\begin{array}{l}\text { No. of initial paths } 100 \\
\text { No. of groups: } 25 \\
\text { No. of iter ati ons } 1000\end{array}$} \\
\hline $\begin{array}{l}\text { Execution } \\
\text { time }(s)\end{array}$ & $\begin{array}{l}\text { No. of } \\
\text { iterat ion }\end{array}$ & $\begin{array}{l}\text { Le ngt h of } \\
\text { path }(\mathrm{m})\end{array}$ \\
\hline 0.994 & 15 & 262.601 \\
\hline 1159 & 22 & 262.601 \\
\hline 1141 & 10 & 262.601 \\
\hline 1085 & 12 & 262.601 \\
\hline 1129 & 14 & 262.601 \\
\hline 1068 & 15 & 262.601 \\
\hline 1132 & 7 & 262.601 \\
\hline 1104 & 16 & 262.601 \\
\hline 1108 & 21 & 262.601 \\
\hline 1050 & 6 & 262.601 \\
\hline
\end{tabular}

Table 1: Test of the evolutionary algorithm with 10 points. The algorithm is configured with 100 initial paths and launched several times. Each time, the algorithm converges rapidly (6 to 22 iterations) to the same solution (path of $262.601 \mathrm{rn}$ ). 


\begin{tabular}{|c|c|c|c|c|c|}
\hline \multicolumn{6}{|c|}{$\begin{array}{l}\text { No. of points to be reached: } 20 \\
\text { No. of possible paths: } 6.0823 e+16\end{array}$} \\
\hline \multicolumn{3}{|c|}{$\begin{array}{l}\text { No. of initial paths: } 100 \\
\text { No. of groups: } 25 \\
\text { No. of iterations: } 1000\end{array}$} & \multicolumn{3}{|c|}{$\begin{array}{l}\text { No. of initial paths: } 1000 \\
\text { No. of groups: } 250 \\
\text { No. of iterations: } 1000\end{array}$} \\
\hline $\begin{array}{l}\text { Execution } \\
\text { time (s) }\end{array}$ & $\begin{array}{l}\text { No. of } \\
\text { iterations }\end{array}$ & $\begin{array}{l}\text { Length of } \\
\text { path }(\mathrm{m})\end{array}$ & $\begin{array}{l}\text { Execution } \\
\text { time (s) }\end{array}$ & $\begin{array}{l}\text { No. of } \\
\text { iterations }\end{array}$ & $\begin{array}{l}\text { Length of } \\
\text { path }(\mathrm{m})\end{array}$ \\
\hline 1.035 & 235 & 391.216 & 8.739 & 73 & 380.007 \\
\hline 1.120 & 119 & 380.007 & 8.809 & 72 & 380.007 \\
\hline 1.109 & 87 & 391.216 & 8.839 & 63 & 380.007 \\
\hline 1.102 & 207 & 380.007 & 8.803 & 54 & 380.007 \\
\hline 1.106 & 105 & 380.007 & 8.809 & 63 & 380.007 \\
\hline 1.069 & 648 & 380.007 & 8.876 & 81 & 380.007 \\
\hline 1.096 & 163 & 380.007 & 9.124 & 66 & 380.007 \\
\hline 1.405 & 765 & 391.216 & 8.791 & 56 & 380.007 \\
\hline 1.080 & 104 & 380.007 & 8.905 & 62 & 380.007 \\
\hline 1.102 & 152 & 380.007 & 8.791 & 77 & 380.007 \\
\hline
\end{tabular}

Table 2: Test of the evolutionary algorithm with 20 points. Initialised with 100 paths, the algorithm gives sometimes not a good approximation (path of $391.216 \mathrm{~m}$ ).

In an example with 20 points to be reached (see table 2), by increasing the number of initial paths to 1000 , the algorithm gives each time the same solution (path of 380.007 $\mathrm{m})$. Considering, the computational time increases from $1 \mathrm{~s}$ to more than $8 \mathrm{~s}$.

\begin{tabular}{|c|c|c|c|c|c|c|c|c|}
\hline \multicolumn{9}{|c|}{$\begin{array}{l}\text { No. of points to be reached: } \mathbf{5 0} \\
\text { No. of possible paths: } 3.0414 \mathrm{e}+62\end{array}$} \\
\hline \multicolumn{3}{|c|}{$\begin{array}{l}\text { No. of initial paths: } 100 \\
\text { No. of groups: } 25 \\
\text { No. of iterations: } 1000\end{array}$} & \multicolumn{3}{|c|}{$\begin{array}{l}\text { No. of initial paths: } 1000 \\
\text { No. of groups: } 250 \\
\text { No. of iterations: } 1000\end{array}$} & \multicolumn{3}{|c|}{$\begin{array}{l}\text { No. of initial paths: } \mathbf{1 0 0 0 0} \\
\text { No. of groups: } 2500 \\
\text { No. of iterations: } 1000\end{array}$} \\
\hline $\begin{array}{l}\text { Execution } \\
\text { time }(s)\end{array}$ & $\begin{array}{l}\text { No. of } \\
\text { iterations }\end{array}$ & $\begin{array}{l}\text { Length of } \\
\text { path }(\mathrm{m})\end{array}$ & $\begin{array}{l}\text { Execution } \\
\text { time (s) }\end{array}$ & $\begin{array}{l}\text { No. of } \\
\text { iterations }\end{array}$ & $\begin{array}{l}\text { Length of } \\
\text { path }(\mathrm{m})\end{array}$ & $\begin{array}{l}\text { Execution } \\
\text { time }(s)\end{array}$ & $\begin{array}{l}\text { No. of } \\
\text { iterations }\end{array}$ & $\begin{array}{l}\text { Length of } \\
\text { path }(\mathrm{m})\end{array}$ \\
\hline 1.202 & 917 & 565.781 & 10.094 & 589 & 553.606 & 106.070 & 503 & 550.434 \\
\hline 1.198 & 996 & 589.936 & 9.812 & 526 & 565.346 & 110.167 & 497 & 550.434 \\
\hline 1.182 & 953 & 615.035 & 9.804 & 545 & 569.193 & 108.151 & 549 & 545.639 \\
\hline 1.201 & 930 & 583.353 & 9.767 & 727 & 550.434 & 108.285 & 715 & 550.434 \\
\hline 1.203 & 932 & 594.105 & 9.895 & 603 & 566.987 & 108.616 & 455 & 545.639 \\
\hline 1.019 & 976 & 573.257 & 9.866 & 611 & 545.639 & 106.924 & 475 & 545.639 \\
\hline 1.357 & 963 & 578.070 & 9.896 & 601 & 556.779 & 107.919 & 401 & 550.434 \\
\hline 1.167 & 900 & 572.387 & 9.967 & 657 & 568.236 & 110.111 & 485 & 550.434 \\
\hline 1.252 & 962 & 595.712 & 9.951 & 837 & 576.623 & 107.579 & 859 & 545.639 \\
\hline 1.213 & 956 & 603.251 & 9.863 & 789 & 545.639 & 108.556 & 519 & 550.434 \\
\hline
\end{tabular}

Table 3: Test of the evolutionary algorithm with 50 points. Initialised with 100 paths, the obtained approximations are dispersed and give long paths (the smaller path is $565.781 \mathrm{~m}$ long).

In an example with 50 points to be reached, with 1000 initial paths, the obtained approximations are less dispersed and the paths have lower distances. By increasing the number of initial paths to 10000 , the algorithm converges towards better results, but in return, the computational time increase to nearly 2 minutes (see table 3 ).

\section{Conclusion and further work}

This paper presents an original and fully operational method to carry out trajectory planning tasks for a car-like mobile robot to process and cover previously determined spots in a pasture. An approximation algorithm is used to define targeted areas, gathering the spots with non-convex and convex hulls. These hulls are delimited by stair-shaped limits 
w.r.t. to the working width of the robot. Next, to define the optimal order to process the hulls and minimise the travel distance for the robot, an evolutionary algorithm is proposed by solving the TSP between the CoG-s of each hull. Finally, based on the kinematic and dynamic properties of the robot, the final trajectory is generated. The capabilities of the proposed approaches are highlighted through the trajectory planning on several datasets.

Obviously, the computational time of this algorithm will increase w.r.t. the initial population size. However, as this path planning algorithm can be carried out off-line, the computational times do not constrain directly the goal and thus an appropriate amount of time can be spent in finding a good approximation for solving the problem addressed.

Improvements can be achieved considering the strategy used for covering the hulls by the robot, as well as the formulation of the TSP problem. The coverage trajectories of the robot are composed of parallel straight lines separated by the distance corresponding to the working width of the robot. These lines are connected by large loop turn manoeuvres. The drawback of this approach is that it increases the travel distance of the robot and requires a large area for turning onto the adjacent track. To improve this point, other approaches will be studied based on the junction of non-adjacent parallel lines and on the generation of spiral-shaped trajectories to limit the number of manoeuvres. The TSP considers the minimal Euclidean distance between the points to be reached. However, several close points may require large manoeuvres for the non-holonomic robot that may lead to non-optimal solutions. Moreover, as the junction points are calculated after the path optimisation, the resultant path could lead to a suboptimal solution. These aspects will be taken into account in future development by integrating both the steering capacity of the robot and the junction points in the path optimisation algorithm. 


\section{Appendix A}

\begin{tabular}{|c|c|c|c|c|c|c|c|c|c|c|c|c|c|}
\hline \multicolumn{2}{|c|}{ W1 } & & 12 & & 3 & & V4 & & $\sqrt{5}$ & & V6 & & \\
\hline$x(m)$ & $y(m)$ & $x(\mathrm{~m})$ & $y(m)$ & $\times(m)$ & $y(m)$ & $x(m)$ & $y(m)$ & $x(m)$ & $y(m)$ & $x(m)$ & $y(m)$ & $x(\mathrm{~m})$ & $y(m)$ \\
\hline 5.30 & -8.82 & 73.43 & -62.96 & 241.14 & -46.71 & 104.52 & -208.12 & 182.95 & -118.44 & 36.74 & -143.19 & 331.81 & -71.69 \\
\hline 5.52 & -9.79 & 74.57 & -67.83 & 243.87 & -45.21 & 101.17 & -203.43 & 185.18 & -119.17 & 38.79 & -147.53 & 332.83 & -69.03 \\
\hline 8.71 & -19.00 & 71.77 & -47.08 & 244.11 & -41.88 & 100.71 & -201.48 & 181.33 & -93.95 & 33.55 & -125.14 & 331.00 & -66.79 \\
\hline 2.87 & -3.60 & 76.86 & -64.45 & 240.24 & -25.33 & 100.48 & -200.51 & 184.29 & -106.60 & 33.32 & -124.16 & 330.96 & -70.94 \\
\hline 5.06 & -0.69 & 74.05 & -48.08 & 240.40 & -21.60 & 100.23 & -195.03 & 187.02 & -118.29 & 40.96 & -152.41 & 330.32 & -59.15 \\
\hline 7.04 & -7.32 & 77.25 & -57.35 & 240.62 & -22.58 & 101.14 & -198.92 & 182.47 & -94.45 & 43.46 & -163.12 & 330.09 & -58.18 \\
\hline 10.88 & -23.88 & 75.88 & -51.51 & 244.50 & -39.13 & 102.05 & -202.82 & 185.94 & -96.11 & 42.95 & -156.56 & 331.64 & -60.43 \\
\hline 13.10 & -29.00 & 75.65 & -50.54 & 247.00 & -49.84 & 106.36 & -207.21 & 189.36 & -110.72 & 34.76 & -117.17 & 331.87 & -61.40 \\
\hline 11.05 & -20.24 & 73.83 & -42.75 & 245.48 & -38.95 & 101.87 & -197.65 & 192.11 & -118.10 & 36.85 & -117.32 & 331.82 & -65.25 \\
\hline 9.68 & -14.40 & 79.39 & -62.10 & 245.89 & -36.30 & 102.37 & -186.62 & 187.78 & -99.60 & 38.22 & -123.16 & 332.05 & -53.37 \\
\hline 8.05 & -7.60 & 78.25 & -52.85 & 249.29 & -46.42 & 105.56 & -200.25 & 186.87 & -95.70 & 38.68 & -125.11 & 333.20 & -64.92 \\
\hline 6.01 & -1.22 & 78.43 & -40.45 & 244.96 & -27.92 & 106.56 & -208.04 & 190.98 & -108.88 & 38.90 & -126.09 & 332.90 & -65.86 \\
\hline 10.15 & -12.01 & 78.88 & -42.39 & 248.45 & -34.09 & 109.81 & -206.39 & 193.63 & -115.79 & 48.93 & -168.93 & 336.88 & -68.62 \\
\hline 12.66 & -22.73 & 80.71 & -50.18 & 248.90 & -31.61 & 102.36 & -182.22 & 189.98 & -100.21 & 40.84 & -125.59 & 334.73 & -60.46 \\
\hline 14.46 & -26.04 & 80.24 & -43.81 & 249.36 & -29.19 & 102.98 & -180.47 & 193.14 & -109.32 & 47.47 & -149.54 & 334.28 & -58.51 \\
\hline 13.78 & -23.12 & 82.40 & -48.64 & 248.68 & -26.27 & 104.81 & -188.26 & 194.73 & -116.13 & 41.49 & -119.58 & 332.45 & -50.72 \\
\hline 13.55 & -22.14 & 87.39 & -65.56 & 248.22 & -24.32 & 107.54 & -199.95 & 193.70 & -107.31 & 44.95 & -129.98 & 334.58 & -55.41 \\
\hline 10.36 & -8.51 & 85.79 & -58.74 & 255.66 & -47.33 & 106.46 & -203.67 & 197.70 & -106.87 & 40.85 & -112.46 & 335.26 & -66.85 \\
\hline 8.77 & -6.11 & 83.74 & -49.98 & 252.00 & -27.29 & 109.17 & -207.04 & 194.28 & -92.26 & 48.60 & -141.19 & 336.96 & -67.82 \\
\hline 12.25 & -2.58 & 89.67 & -66.54 & 255.64 & -42.87 & 111.18 & -202.64 & 194.84 & -90.27 & 51.56 & -153.85 & 337.95 & -67.79 \\
\hline 13.46 & -12.98 & 83.97 & -42.27 & 256.10 & -44.81 & 108.30 & -198.82 & 198.26 & -104.87 & 51.69 & -150.01 & 339.58 & -66.71 \\
\hline 16.23 & -20.43 & 88.29 & -56.25 & 256.87 & -43.74 & 106.71 & -192.00 & 198.68 & -102.26 & 50.33 & -144.17 & 336.71 & -60.12 \\
\hline 18.06 & -28.22 & 89.53 & -52.78 & 255.51 & -37.90 & 105.50 & -182.45 & 200.96 & -107.63 & 50.54 & -140.72 & 335.34 & -54.28 \\
\hline 15.57 & -13.23 & 90.59 & -52.90 & 255.05 & -35.95 & 107.55 & -191.22 & 203.68 & -114.84 & 52.59 & -149.48 & 335.82 & -51.94 \\
\hline 14.89 & -10.31 & 91.11 & -41.96 & 253.46 & -29.14 & 107.78 & -192.19 & 200.09 & -95.14 & 54.26 & -152.19 & 339.29 & -53.58 \\
\hline 16.04 & -1.98 & 97.03 & -67.27 & 252.09 & -23.30 & 112.87 & -201.42 & 203.51 & -109.75 & 51.29 & -139.53 & 342.07 & -64.48 \\
\hline 18.74 & -18.01 & 98.48 & -69.08 & 251.86 & -22.32 & 110.29 & -198.54 & 205.11 & -116.56 & 50.06 & -129.86 & 340.57 & -50.30 \\
\hline 17.83 & -14.11 & 97.80 & -66.16 & 252.86 & -22.22 & 108.47 & -190.75 & 204.95 & -111.50 & 50.79 & -124.23 & 342.00 & -59.91 \\
\hline 17.15 & -11.19 & 96.04 & -49.89 & 256.51 & -37.80 & 106.42 & -181.99 & 202.90 & -102.74 & 54.21 & -138.83 & 343.38 & -53.51 \\
\hline 17.40 & -7.80 & 98.95 & -49.14 & 258.01 & -39.80 & 106.19 & -181.01 & 205.23 & -108.30 & 55.58 & -144.67 & 343.84 & -51.11 \\
\hline 17.84 & -9.74 & & & 257.78 & -38.83 & 108.10 & -184.78 & 205.91 & -111.22 & 58.54 & -157.33 & 344.07 & -52.08 \\
\hline 18.30 & -11.69 & & & 256.87 & -34.93 & 111.98 & -196.95 & 207.97 & -115.64 & 60.97 & -163.31 & 343.66 & -59.71 \\
\hline 20.35 & -20.45 & & & 254.49 & -20.40 & 111.75 & -195.98 & 206.83 & -110.77 & 53.88 & -128.66 & 345.19 & -62.11 \\
\hline 19.78 & -9.27 & & & 256.09 & -27.21 & 108.79 & -183.32 & 204.76 & -93.14 & 56.62 & -140.34 & 348.63 & -58.21 \\
\hline 23.43 & -24.85 & & & 257.23 & -32.08 & 109.18 & -180.61 & 208.43 & -104.44 & 59.35 & -152.03 & 350.73 & -57.76 \\
\hline 22.94 & -13.99 & & & 261.33 & -49.61 & 112.37 & -194.24 & 206.71 & -92.70 & 63.00 & -167.61 & 348.71 & -55.64 \\
\hline 23.40 & -15.94 & & & 259.97 & -39.42 & 112.82 & -196.19 & 207.64 & -92.30 & 53.27 & -121.65 & 350.83 & -54.78 \\
\hline 25.45 & -24.70 & & & 256.55 & -24.82 & 112.15 & -184.55 & 208.78 & -97.17 & 52.36 & -117.75 & 349.27 & -52.36 \\
\hline 23.90 & -9.33 & & & 257.57 & -24.75 & 118.92 & -199.43 & 213.34 & -116.65 & 52.49 & -113.93 & 354.43 & -56.01 \\
\hline 26.18 & -19.07 & & & 259.39 & -32.54 & 114.88 & -191.82 & 211.32 & -103.62 & 52.72 & -114.90 & 353.05 & -50.89 \\
\hline 28.46 & -28.80 & & & 260.53 & -37.41 & 113.97 & -187.92 & 214.94 & -110.31 & 64.34 & -164.56 & 356.82 & -56.45 \\
\hline 29.29 & -27.97 & & & 260.76 & -38.38 & 113.16 & -180.08 & 214.03 & -106.42 & 65.55 & -165.34 & 355.56 & -50.14 \\
\hline 27.47 & -20.18 & & & 262.12 & -44.23 & 120.56 & -197.81 & 212.33 & -90.38 & 64.18 & -159.50 & 356.47 & -53.09 \\
\hline 21.43 & -3.80 & & & 262.54 & -41.64 & 120.02 & -196.99 & 216.69 & -104.63 & 57.56 & -126.81 & 357.03 & -53.91 \\
\hline 21.60 & -2.81 & & & 261.18 & -35.79 & 114.28 & -180.45 & 218.06 & -110.47 & 58.70 & -131.68 & 363.07 & -52.46 \\
\hline 26.31 & -10.84 & & & 260.95 & -34.82 & 116.98 & -187.63 & 218.95 & -105.52 & 58.93 & -132.66 & 363.26 & -51.19 \\
\hline 28.36 & -19.61 & & & 257.76 & -21.19 & 122.36 & -198.80 & 221.23 & -115.25 & 59.61 & -135.58 & 365.21 & -51.26 \\
\hline 23.77 & -4.96 & & & 259.35 & -23.61 & 118.60 & -185.76 & 220.77 & -108.90 & 60.20 & -133.71 & 366.70 & -50.00 \\
\hline 29.99 & -9.00 & & & 260.95 & -30.43 & 122.99 & -199.02 & 221.75 & -108.68 & 59.74 & -127.37 & 365.72 & -50.29 \\
\hline 29.71 & -3.56 & & & 262.77 & -38.22 & 119.22 & -184.04 & 221.98 & -109.66 & 68.45 & -160.16 & 366.71 & -50.26 \\
\hline & & & & 264.14 & -44.06 & 120.29 & -184.23 & 223.11 & -114.52 & 63.89 & -140.69 & & \\
\hline & & & & 264.82 & -46.98 & 120.52 & -185.20 & 224.35 & -106.65 & 59.96 & -119.49 & & \\
\hline & & & & 262.53 & -32.81 & 121.66 & -190.07 & 228.02 & -117.94 & 61.78 & -127.28 & & \\
\hline & & & & 262.07 & -30.86 & 122.03 & -187.27 & 227.05 & -109.39 & 69.07 & -158.44 & & \\
\hline & & & & 265.32 & -40.32 & 120.67 & -181.42 & 231.26 & -118.61 & 69.78 & -157.10 & & \\
\hline & & & & 267.14 & -48.10 & 120.44 & -180.45 & 232.10 & -117.82 & 64.80 & -131.42 & & \\
\hline & & & & 265.63 & -37.28 & 122.75 & -185.95 & 235.58 & -115.14 & 69.36 & -150.90 & & \\
\hline & & & & 267.48 & -40.79 & 123.58 & -191.79 & 236.18 & -104.50 & 62.83 & -118.63 & & \\
\hline & & & & 266.31 & -27.02 & 124.08 & -187.24 & 239.38 & -113.80 & 65.38 & -116.36 & & \\
\hline & & & & 268.99 & -25.32 & 122.94 & -182.37 & 240.68 & -114.99 & 69.32 & -120.03 & & \\
\hline & & & & & & 123.46 & -180.22 & 238.05 & -94.96 & & & & \\
\hline & & & & & & 126.28 & -187.87 & 242.63 & -105.76 & & & & \\
\hline & & & & & & 127.04 & -182.32 & 240.58 & -97.00 & & & & \\
\hline & & & & & & 126.81 & -181.34 & 243.03 & -103.07 & & & & \\
\hline & & & & & & 128.19 & -190.05 & 242.12 & -94.79 & & & & \\
\hline & & & & & & 128.54 & -192.87 & 241.21 & -90.89 & & & & \\
\hline & & & & & & 133.03 & -189.91 & 244.18 & -90.43 & & & & \\
\hline & & & & & & 129.71 & -180.59 & 246.91 & -102.11 & & & & \\
\hline & & & & & & 130.33 & -188.29 & 249.12 & -115.69 & & & & \\
\hline & & & & & & 135.12 & -190.50 & 248.97 & -102.15 & & & & \\
\hline & & & & & & 135.09 & -189.50 & & & & & & \\
\hline & & & & & & 132.32 & -186.86 & & & & & & \\
\hline & & & & & & 134.69 & -191.66 & & & & & & \\
\hline & & & & & & 136.83 & -189.79 & & & & & & \\
\hline & & & & & & 135.79 & -188.56 & & & & & & \\
\hline & & & & & & 138.73 & -184.11 & & & & & & \\
\hline & & & & & & 137.16 & -181.69 & & & & & & \\
\hline & & & & & & 138.11 & -182.52 & & & & & & \\
\hline & & & & & & 138 & & & & & & & \\
\hline & & & & & & 139.92 & -180.41 & & & & & & \\
\hline
\end{tabular}

Table 4: Datasets of the areas with weeds (numbered from 1 to 7 on the figure 1c). 
Acknowledgments: This research was carried out within the frame of the ICT-AGRI project i-LEED (Advanced cattle feeding on pasture through innovative pasture management, 2013/2017) funded within the 2nd ICT-AGRI ERA-NET and financially supported by a grant from NCPs: the German Federal Ministry of Food, Agriculture and Consumer Protection (BMELV) through the Federal Office for Agriculture and Food (BLE) grant number 2812ERA058 and 2812ERA059, the French National Research Agency (ANR) grant number 12-ICTA-0002-01 and 12-ICTA-0002-02 and the Scientific and Technological Research Council of Turkey (TUBITAK) grant number 1120 464. Web site: $h t t p: / / w w w . i-$ leed.eu. The authors thank all employees of the National Research Institute of Science and Technology for Environment and Agriculture (Irstea) and the Bavarian State Research Center for Agriculture (LfL) who were involved in this work, for their excellent cooperation.

Author contributions: Christophe Cariou contributed to the design and implementation of the evolutionary algorithm and the path generation for the robot taking into account its working width and kinematic and dynamic properties. Zoltan Gobor contributed to the generation of the datasets and the design of the approximation algorithm to define the non-convex and convex hulls.

Conflicts of interest: The authors declare no conflict of interest.

\section{References}

Alhanjouri, M. (2017). Optimization techniques for solving traveling salesman problem. International journal of advanced research in computer science and software engineering, (7)3, 165-174.

Böttinger, S., Doluschitz, R., Volz, R., Paterson, S., \& Jenane, C. (2010). World trends and evolution of the agricultural machinery manufacturing sector. In AgEng 2010, International conference on Agricultural Engineering, Clermont-Ferrand, France.

Cariou, C., Gobor, Z., Seiferth, B., \& Berducat, M. (2017). Mobile robot trajectory planning under kinematic and dynamic constraints for partial and full field coverage. Journal of Field Robotics, doi:10.1002/rob.21707.

Christensen, S., Søgaard, H. T., Kudsk, P., Nørremark, M., Lund, I., Nadimi E. S., \& Jørgensen, R. (2009). Site-specific weed control technologies. Weed Research, 49(3), 233-241.

Contreras-Bolton, C., \& Parada, V. (2015). Automatic combination of operators in a genetic algorithm to solve the traveling salesman problem. PLOS ONE, 10(9).

Coyette, C., \& Schenk, H. (eds.) (2011). Agriculture and fishery statistics, Eurostat, European Union.

Davendra, D. (eds) (2010). Traveling salesman problem, theory and applications, InTech.

Gerhards R., Wyse-Pester, D. Y., \& Mortensen, D.A. (1996). Spatial stability of weed patches in agricultural fields. Precision Agriculture, 495-504.

Gobor, Z. (2017). Finding the convex or non-convex hull of a random number of vertices - simple task? In Proceedings of the 4th International Conference and Workshop Mechatronics in Practice and Education - MECHEDU 2017, Subotica, Serbia, 14-19. 
Gobor, Z., Cariou, C., Seiferth, B., Thurner, S., Feucker, W., Tessier, C., Tekin, B., \& Berducat, M. (2015). Advanced pasture management through innovative robotic pasture maintenance. In IROS Workshop on Agri-Food Robotics, Hamburg, Germany.

Kirk, J. (2007). Traveling Salesman Problem: Genetic Algorithm. In MATLAB Central File EXchange; Natick, MA, USA.

Krohmann, P., Gerhards, R., \& Kühbauch, W. (2006). Spatial and temporal definition of weed patches using quantitative image analysis. Journal of Agronomy and Crop Science, 192(1), 72-78.

Lamb, D. W., \& Weedon, M. (1998). Evaluating the accuracy of mapping weeds in fallow fields using airborne digital imaging: Panicumeffusum in oilseed rape stubble. Weed Research, 38(6), 443-451.

Lottes, P., Hörferlin, M., Sander, S., \& Stachniss, C. (2016). Effective vision-based classification for separating sugar beets and weeds for precision farming. Journal of Field Robotics, doi:10.1002/rob.21675.

Munoz, V.F., \& Ollero, A. (1996). Smooth trajectory planning method for mobile robots. IEEESMC Symposium on Robotics and Cybernetics.

OECD/FAO (2012). OECD-FAO Agricultural Outlook 2012-2021. OECD Publishing and FAO.

Pedersen, S. M., Fountas, S., \& Blackmore, S. (2007). Economic potential of robots for high value crops and landscape treatment. Precision Agriculture 2007, ed. J. Stafford, V. Wageningen Academic Publishers, 457-464.

Potvin J.Y. (1996). Genetic algorithms for the traveling salesman problem. Annals of Operations Research, 339-370.

Ray, D. K., Mueller, N. D., West, P. C., \& Foley, J. A. (2013). Yield trends are insufficient to double global crop production by 2050. In PloS one, 8(6).

Sabelhaus, D., Roben, F., Helligenand, L. P. M., \& Lammers, P. S. (2013). Using continuouscurvature paths to generate feasible headland turn manoeuvres. Biosystems Engineering, 116(4), 399-409.

Seiferth, B., Cariou, C., \& Gobor, Z. (2016). Control and guidance system for optimal maintenance operations on pastures by an autonomous mobile machine. In MCG 2016, 5th International Conference on Machine Control and Guidance, Vichy, France.

Sørensen, C. G., Jørgensen, R. N., Maagaard, J., Bertelsen, K. K., Dalgaard, L. and Nørremark, M. (2010). Conceptual and user-centric design guidelines for a plant nursing robot. Biosystems Engineering, 105(1), 119-129.

Wang, D., \& Low, C. (2007). An analysis of wheeled mobile robots in the presence of skidding and slipping: Control design perspective. In IEEE International Conference on Robotics and Automation, Roma, Italy, 2379-2384. 